\title{
RESENHA
}

\section{Teologia negra como movimento antirracista}

PACHECO, Ronilso. Teologia Negra: o sopro antirracista do Espírito. Brasília: Novos Diálogos; São Paulo: Editora Recriar, 2019.

\section{Waleska Miguel Batista'}

1 Universidade Presbiteriana Mackenzie, São Paulo, São Paulo, Brasil. E-mail: mbwaleska@gmail.com. ORCID: https://orcid.org/0000-0001-6700-9577.

Resenha recebida em 8/12/2019 e aceita em 17/05/2020.

\section{(cc) $\mathrm{EY}$}

This work is licensed under a Creative Commons Attribution 4.0 International License. 


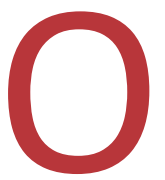

autor do livro, pastor da Igreja Evangélica Comunidade Batista em São Gonçalo, quebra o paradigma de que os cristãos evangélicos são reacionários e avessos a demandas sociais. Silvio Luiz de Almeida, filósofo e jurista, professor, presidente do Instituto Luiz Gama, afirmou que "estamos diante de um texto escrito por um intelectual de alto nivel, um pensador sofisticado que, sem renegar seu lugar no mundo, oferece-nos um trabalho analítico, crítico, de inúmeras referências" (apud PACHECO, 2019: 9).

O Prefácio do livro "Teologia negra: O sopro antirracista do Espírito" foi elaborado por Silvio Luiz de Almeida, que apresenta o livro como forma de esperança e libertação em meio às violências emocionais e físicas direcionadas contra negros, mulheres e membros de religiões de matriz africana. Ele descreve a teologia apresentada por Ronilso como a manifestação dos oprimidos e marginalizados, bem como dos sobreviventes das perseguições e humilhações suportadas em razão do racismo. ${ }^{1}$

O livro é estruturado com introdução, quatro capítulos e conclusão. O primeiro capítulo, intitulado "Sobre a teologia", mostra como a teologia nasce no deserto, como ela é doadora de sentido na relação social. No segundo capítulo, "O sopro antirracista do Espírito", o autor narra a relevância de uma Teologia Negra, o seu surgimento e as suas principais chaves e características. No terceiro capítulo, o autor apresenta o mapeamento dos debates da Teologia Negra na sistemática política, no movimento das mulheres e na diáspora. E no quarto capítulo, o autor sugere a possibilidade de uma Teologia Negra brasileira, a partir do caminho de reconciliação com a África, com a hermenêutica bíblica comunitária e quilombista.

O nome do livro reflete o conceito difundido nos anos 1960 nos Estados Unidos por James Cone, que desenvolveu a Teologia Negra a partir da concepção de que o povo negro sempre foi resistente às artimanhas da estrutura dominante que o subalternava, não reconhecendo sua humanidade. Agostinho José Pereira, pastor, também conhecido

\footnotetext{
1 "O livro que aqui se apresenta é uma oportunidade para aqueles que creem no Deus cristão e querem um mundo melhor, que a luta antirracista - inclusive contra o racismo religioso, que estimula a perseguição às religiões de matriz africana - é um imperativo na sua relação com Deus e a comunidade. E para aqueles que não creem no Deus cristão, mas que igualmente querem um mundo melhor, Ronilso Pacheco ensina que a luta antirracista, concebida em múltiplas frentes de batalha, pode ser um fator de unidade política essencial em um processo de transformação" (ALMEIDA apud PACHECO, 2019: 11).
} 
como Lutero Negro, profético e libertador, foi apontado, segundo o autor, como símbolo de combate contra o racismo. ${ }^{2}$

O estudo da Teologia Negra de James Cone surgiu no mesmo período que as lutas pelos Direitos Civis, e podemos citar nomes como Martin Luther King Junior e Malcolm X, e posteriormente na África do Sul, em razão do regime apartheid, ${ }^{3}$ onde podemos mencionar o Arcebispo Desmond Tutu.

O autor afirma que a discussão sobre uma Teologia Negra faz sentido quando há o reconhecimento de que as sociedades colonizadas foram submetidas às imposições eurocêntricas, na medida em que o racismo e o regime escravocrata foram mecanismos utilizados como forma de determinação das relações sociais, políticas, econômicas e religiosas. O autor entende que "Sem a compreensão de como o mundo é "racializado" a partir da Europa, a Teologia Negra perde seu pano de fundo" (PACHECO, 2019: 17).

A Teologia Negra tem força nos movimentos religiosos, não importando a sua crença, pois está presente nas igrejas protestantes, católicas e de matriz africana. Inclusive, a Revolução Haitiana foi colocada como uma conquista alcançada pela manifestação do vodu, segundo as crenças populares.

Bernand S. Cohn (1928: 143) narrou a dominação da Europa na Índia e evidencia que todos os colonizadores utilizavam da religião para demonizar o grupo dominado, bem como impor novos costumes religiosos e culturais. ${ }^{4}$ Gilberto Freyre (2003) no livro Casa Grande e Senzala narrou que o catecismo dos indígenas pelos jesuítas refletiu, em grande parte, este mesmo quadro. A religião foi utilizada como forma de imposição de novos costumes visando à dominação estrutural.

\footnotetext{
20 autor narra que "Sempre houve luta por liberdade e resistência. Todas as estruturas que instalaram sistemas de poder tiveram de lidar com as fissuras forçadas por aqueles e aquelas que não calaram ou recuaram" (PACHECO, 2019: 15). Estas pessoas não possuem nomes de destaque, tampouco são homenageadas dando seus nomes a praças, ruas ou teatros, mas foram essenciais às lutas de combate às desigualdades.

3 "O apartheid na África do Sul não pode ser bem compreendido sem se entender, também, o papel da Igreja Reformada Holandesa (IRH) no país. De orientação teológica neocalvinista, a IRH teve papel determinante no apartheid enquanto ideologia (a defesa de um desenvolvimento dos brancos separados dos negros, "justificado" teologicamente) e enquanto política de Estado - com a decretação em 1948 do apartheid como política oficial. Neste momento, o Partido Nacional e a IRH são um, e estão convictos de que eles estariam imbuídos da missão de trazerem o cristianismo e a civilização para o continente africano" (PACHECO, 2019: 108 [grifo original]).

4 "Num mundo em que a religião ainda é senhora e dá as cartas (mesmo quando o pensamento ilustrado ocidental se vê lutando contra a ingerência da lgreja), colonialismo, racismo, imperialismo e capitalismo não viveriam sem uma alma, e sua alma é o cristianismo ocidental e sua Teologia. A modernidade traz consigo o cristianismo para legitimar teologicamente tanto a colonização quanto a escravidão" (PACHECO, 2019: 51).
} 
Da mesma forma, o continente africano ainda é estigmatizado como amaldiçoado, bem como composto por criaturas amaldiçoadas por Deus, o que afasta o reconhecimento de qualquer humanidade dos homens negros e mulheres negras. Com isso, as histórias cristãs impostas e difundidas massivamente na colonização transformaram personagens bíblicos negros em pessoas com estereótipo europeu.

Certamente que a religião cristã europeia não é o fundamento do racismo, mas serviu como justificativa utilizada para legitimar práticas racistas. Silvio Luiz de Almeida (2018), Achille Mbembe (2014), Michele Alexander (2017), entre outros pesquisadores, narram que o racismo é estrutural e construído socialmente a partir dos interesses do sistema econômico, e a igreja não fica afastada dessa lógica.

Ronilso Pacheco, a partir das leituras de James Cone, entende que a Teologia Negra está relacionada com a saída dos Hebreus do deserto a caminho da liberdade. 0 deserto, para estes autores, é a travessia que transforma a condição de escravo para liberto, e este terá a definição do seu território e povo. "A diáspora de outrora e de agora, une duas narrativas complementares de luta por libertação, autonomia e reconhecimento do lugar de pertença, de onde se parte e de onde se foi arrancado" (PACHECO, 2019: 68).

$\mathrm{O}$ autor narra que as lutas de libertação estiveram relacionadas com as tradições e ancestralidade, inclusive porque Jesus Cristo morreu para que todas as pessoas fossem livres e não apenas para que as pessoas europeias ou de uma teologia específica tivessem a liberdade garantida (PACHECO, 2019: 73).

A história do Velho Testamento em que o povo escolhido saiu da escravidão à Terra Prometida "mostra a libertação, esperança e redenção do Novo Mundo", sendo mais relevante para os discursos libertadores dos negros de hoje do que relatos para os contos de Natal (HALL, 2013: 31).

O acréscimo do adjetivo negra a teologia foi uma forma de ressignificar a teologia, que era excludente e preconceituosa, para incluir aqueles marginalizados e oprimidos, a tal ponto que a Teologia Negra não é uma categoria universalizante. A Teologia Negra quer concentrar atenção às minorias (homens negros, mulheres negras, religiões de matriz africana).

Mesmo assim, não significa que a Teologia Negra seja, por si, capaz de promover a liberdade, já que é um discurso que só pode ser posto em prática. E pôr o discurso em prática tem obstáculos. Não é só sair da colônia, também é preciso ir contra o racismo. Só sair da colônia não vai impedir ou reduzir a escravidão, pois esta é mantida pelo racismo 
contra o qual esta teologia se opõe. Isto quer dizer, não adianta vivermos no período póscolonial se não combatermos o sistema e as estruturas que reproduzem as disparidades sociais e raciais.

É nesse sentido, também, que o deserto é utilizado como principal exemplo de luta pela liberdade, já que rompe com a normalidade imposta. A Teologia Negra busca construir caminhos de libertação, sem que o ódio e os ressentimentos do passado atrapalhem a construção de uma lógica social em que não seja mais necessário ressignificar conceitos para gerar inclusão. Ou seja, para que não seja (mais) necessária uma Teologia Negra.

O autor mostra que a Teologia em nenhum momento foi capaz de reprimir o comportamento dos racistas, por isso que Teologia Negra surgiu como forma de evidenciar que racismo e outras discriminações não são aceitáveis.

As principais características da Teologia Negra são a territorialidade, que é local em que se dão experiências e a construção de sua história. ${ }^{5} \mathrm{~A}$ afrocentricidade como forma de colocar a África como referência, bem como as contribuições advindas deste continente com vasta diversidade cultural, religiosa e identitária. A ancestralidade e a tradição como forma de memória de como os negros chegaram aqui. ${ }^{6} \mathrm{~A}$ corporalidade tem lugar-chave na Teologia Negra, vez que o corpo negro é o corpo sem proteção, é o corpo estrangeiro e é aquele determinado como o outro, logo, é indesejável. ${ }^{7}$ E não menos importante, o autor destaca a cosmovisão dialogal e includente, dando abertura ao ecumenismo, ao apontar que "não há qualquer possibilidade de conciliação entre Teologia Negra e a demonização das demais religiões de matriz africana" (PACHECO, 2019: 78), pois entente que o Espírito se revela onde quer.

Interessante que as religiões de matriz africana são brutalmente inferiorizadas e demonizadas, contudo, as crenças nos deuses brancos como Zeus e Odin, mitologias da

\footnotetext{
5 "O povo negro reivindica do território não apenas a sua paisagem e natureza, mas a força, a energia, o axé vital, ou em outras palavras evidentes, reivindica sua dimensão religiosa e espiritual que move e inspira sua vida. O território é solo indissociável da manifestação do povo negro" (PACHECO, 2019, p. 64).

6 "Nossos ancestrais negros em diáspora conheceram a violação, a vexação, o deserto enquanto suas terras eram sumariamente invadidas e controladas. Um desmantelamento de famílias que nunca mais voltaram a se reencontrar, seus corpos foram produtos finos do degradado comércio de tráfico humano, com atenção especial para as muitas, milhões, de mulheres negras violentadas, queimadas acusadas de feitiçaria ou testemunhas de morte dos filhos e companheiros" (PACHECO, 2019, p. 70-71).

7 "É o corpo, sempre o corpo nu, não apenas pela ausência de vestes, mas nu sem proteção à violência, aos maus tratos, corpo nu e indefeso diante do controle inclemente do estado e das incertezas, riscos $e$ inseguranças da vida social" (PACHECO, 2019, p. 74). Achille Mbembe (2016, p. 140) narra sobre essas relações de poder são exercidas na medida em que há controle sobre a mortalidade, de modo que o Estado pode se transformar em uma máquina de guerra.
} 
mesma forma, não são tratadas com o mesmo desprezo. Isto acontece porque o primeiro é composto por deuses negros e o segundo por deuses brancos, mas ambos são ofensivos à Verdade bíblica cristã. $\mathrm{O}$ tratamento diferente é visto nos desenhos, na medida em que os deuses brancos são heróis e os deuses negros, vilões e destruidores.

Nesse sentido, é sobretudo o racismo que ergue o muro e divide as relações e neutraliza o afeto, inviabilizando o reconhecimento mútuo entre negro e negras de religiosidades distintas. O cristianismo como "religião dos brancos", e portanto, "norma". O candomblé como "religião dos negros", e portanto, não apenas uma "religião que não é verdadeira", ou "anormal', mas sendo sobretudo "uma religião do mal", "diabólica" (PACHECO, 2019: 145).

A perspectiva do movimento feminista também é abordada pelo autor, mostrando que as mulheres negras foram subalternadas. Mas a Teologia Negra abrange esse grupo vulnerável, e luta para que as mulheres negras sejam valorizadas. $O$ autor narra que o mulherismo é inspirado na memória da ex-escravizada Sojouner Truth que, em Ohio, em 1851, proferiu a pergunta: "E eu não sou uma mulher?”, evocando as peculiaridades que naquela época havia à condição de ser mulher negra. No século XXI, a pergunta realizada por Truth ainda precisa ser feita e respondida, pois as mulheres negras continuam em condição de vulnerabilidade. ${ }^{8}$

Angela Davis (2016) mostra que as mulheres negras são colocadas em subempregos, são alvos de violências sexuais, assim como Silvio Luiz de Almeida (2018) afirma que elas padecem da dupla discriminação por serem negras e mulheres (causas cumulativas).

Com exemplos da vida de Jesus Cristo, o autor afirma que não há motivos para que as mulheres, os negros e as pessoas de outras religiões sejam reprimidas. $O$ autor mostra que Jesus conversou com uma mulher Samaritana, que Deus guardou a vida de Agar e que Ele nunca desprezou qualquer pessoa. Jesus, segundo a Bíblia, realizou milagres não só em favor de judeus, mas também de romanos, que à época oprimiam todos os povos da Palestina. Realizou milagres em favor de fariseus, que dominavam o

\footnotetext{
${ }^{8} \mathrm{~A}$ pergunta também pode levar a reflexão sobre o fato de as mulheres negras terem sido criadas para serem fortes. A estas não foi permitida a chance de sofrerem, adoecerem e serem auxiliadas. Pelo contrário, foi insculpida na formação das mulheres negras a força, quer dizer, mulheres fortes (física e emocionalmente). Mas isso não quer dizer que seja bom, foi uma necessidade para sobreviverem. Lélia Gonzalez (1984) narrou no final do século XX que as mulheres negras eram subalternadas, de modo que sequer eram inseridas no mercado de trabalho para funções como secretarias, administradoras, médicas, pois foi designado que o lugar delas era para atividades de doméstica. "Não adianta serem "educadas" ou estarem "bem vestidas" (afinal, "boa aparência", como vemos nos anúncios de emprego é uma categoria "branca", unicamente atribuível a "brancas" ou "clarinhas") (GONZALEZ, 1984, p. 230).
} 
cenário político em Jerusalém. Não só em favor de homens, mas também em favor de mulheres e crianças. Para além disso, andava e compartilhava seu tempo e sua vivência entre os desprezados e não entre os membros de qualquer elite. Ao mesmo tempo, o autor mostra que é importante lutar, não havendo nenhuma dignidade em ficar aguardando passivamente o que as pessoas fazem da sua vida e com seus corpos.

No último capítulo do livro, o autor apresenta o seu anseio para que a Teologia Negra seja um movimento efetivo na realidade brasileira, a partir do conceito de territorialidade e corporalidade. A complexidade do racismo estrutural no Brasil mostra que a lógica de colônia é muito presente. Aparentemente, cruzamos o deserto, mas a estrutura colonial ainda é real por aqui, logo não existe liberdade.

No livro A Crítica da Razão Negra, Achille Mbembe (2014) afirma que a condição do negro é uma condição universal, pois sempre será relacionada com a ascendência africana. A raça existe em razão do racismo, que designou inclusive a criação do branco, sujeito que vive, e o negro, sujeito passível de morte. ${ }^{9}$

Na escravidão o negro tinha valor econômico, pois era uma mercadoria, por isso a sua morte trazia prejuízos. Contudo, hoje, o negro é um corpo descartável, é um corpo matável, já que no sistema capitalista a sua inserção é de sub-inclusão, e quando não pode ser colocado no mercado, é melhor para a lógica social vigente que seja morto. ${ }^{10}$

Então, com esse raciocínio, é possível adaptar a ideia de África para outros lugares do mundo, por exemplo, nas favelas brasileiras. Este ponto é crucial para o autor que afirma que para que se possa levar a sério a Teologia Negra no Brasil precisamos nos socorrer mais em autores como “Clóvis Moura, Lélia Gonzalez, Sueli Carneiro, Milton Santos e Conceição Evaristo" (PACHECO, 2019: 142), uma vez que as suas pesquisas, contos e concepções da realidade dos negros e negras brasileiros permitem combater especificamente os fundamentos e peculiaridades do racismo.

Importante mencionar que a Teologia Negra está conectada com a Teoria Crítica Racial que também foi constituída em meados dos anos de 1960, nos Estados Unidos, e

\footnotetext{
9 "A branquitude é normativa, é como se fosse uma propriedade, e a partir dela se define o outro. A literatura e a mídia reforçam essa visão das minorias como o outro exótico. As minorias aparecem em papéis de vilão ou como amantes românticas e excessivamente sexistas. Filmes de ficção científica e programas de televisão retratam extraterrestres com características e cores parecidas com minorias" (DELGADO; STEFANCIC 2001: 76 [tradução própria]).

${ }^{10}$ Com a crise econômica e a suposta escassez de emprego, permite-se que os negros morram nas travessias dos mares para a Europa, ou que sejam exterminados pelo Estado por seus sistemas policiais. "A iminência da guerra, a emergência de um conflito e o estresse absoluto dão a tônica para o mundo contemporâneo, em que a vida é subjugada ao poder da morte" (ALMEIDA, 2018: 92).
} 
que critica os conceitos da ordem liberal, igualdade, raciocínio jurídico, racionalismo e os princípios neutros do direito constitucional (DELGADO, STEFANCIC, 2001: 2-3).

O autor do livro afirma que a Teologia Negra será uma forma de libertação, e corretamente não dá importância ao direito como força coercitiva para garantia de um futuro sem que a raça exista. Se a norma jurídica serve para dar sentido as relações sociais, e quem as estabelece é o grupo dominante, massivamente, pessoas interessadas na preservação da mentalidade colonizadora, não podemos esperar que o direito seja capaz de combater o racismo. ${ }^{11}$

Ronilso Pacheco finaliza o livro da seguinte forma:

Foi preciso deixar alguma referência para quem quisesse caminhar pelos passos dados pela Teologia Negra rumo não apenas à derrubada do racismo, mas a um embate frente a frente com a capilaridade da desigualdade, da injustiça e da opressão, onde o racismo também se encontra, a partir da igreja (PACHECO, 2019: 163).

Ao término da leitura do livro, fica evidente que a fé, colocada como forma política contribuiu para a manutenção e reprodução das tensões raciais, de maneira que a Teologia Negra, mais que um movimento religioso, é uma chave para lutar contra o racismo estrutural que insiste em determinar comportamentos e lugares específicos aos negros.

\section{Referências bibliográficas}

ALMEIDA, Silvio Luiz. “O que é racismo estrutural?” Belo Horizonte: Letramento, 2018.

COHN, Bernand S. "Colonialism and its forms of Knowledge". The British in India. Princeton Studies in Culture, Power History, 1928.

DAVIS, Angela. "Mulheres, raça e classe". Tradução Heci Regina Candiani. 1.ed. São Paulo: Boitempo, 2016.

DELGADO, Richard; STEFANCIC, Jean. "Critical Race Theory: An Introduction". New York University Press: New York and Londom, 2001.

FREYRE, Gilberto. "Casa-grande \& senzala: formação da família brasileira sob o regime da economia". 48.ed. São Paulo: Global, 2003.

\footnotetext{
${ }^{11} \mathrm{O}$ direito também é insuficiente para combater o racismo porque a existência de norma jurídica não garante a sua efetividade quando seu sentido contraria estruturas sociais complexas. Por exemplo, no Brasil há uma vasta legislação antirracista, mas sem qualquer efetividade.
} 
GONZALEZ, Lélia. Racismo e Sexismo na Cultura Brasileira. "Revista Ciências Sociais Hoje", ANPOCS, 1984, p. 223-244.

HALL, Stuart. "Da diáspora: identidades e mediações culturais". Organização Liv Sovik; Tradução Adelaide La Guardia Resende [et.al.]. 2.ed. Belo Horizonte: Editora UFMG, 2013.

MBEMBE, Achille. "A crítica da Razão Negra". Tradução de Marta Lança. Lisboa: Antígona, 3. ed, 2014.

MBEMBE, Achille. "Necropolítica: biopoder, soberania, estado de exceção e política de morte". Tradução de Renata Santini. Revisão técnica Cezar Bartholomeu. Arte \& ensaios. Revista do PPGAV / EBA / UFRJ, n. 32, dex/2016.

PACHECO, Ronilso. "Teologia Negra: o sopro antirracista do Espírito". Brasília: Novos Diálogos; São Paulo: Editora Recriar, 2019.

Sobre a autora

Waleska Miguel Batista

É doutoranda em Direito Político e Econômico pela Universidade Presbiteriana Mackenzie, Mestra em Sustentabilidade e Graduada em Direito pela Pontifícia Universidade Católica de Campinas. Integra o grupo de pesquisa Estado e Direito no pensamento social brasileiro, vinculado à UPM. Bolsista integral CAPES. E-mail: mbwaleska@gmail.com

A autora é a única responsável pela redação da resenha. 